\title{
Desenvolvimento e Vivir Bien na Bolívia Plurinacional
}

\author{
Renata Albuquerque de Moraes \\ Doutoranda em Antropologia Social \\ Universidade de Brasília
}

Resumo: A proposta de construção de uma estrada através do Território Indígena e Parque Nacional Isiboro Sécure (TIPNIS) disparou uma nova onda de mobilizações indígenas na Bolívia a partir de 2011. O governo, suas políticas e o próprio proceso de cambio protagonizado pelo presidente Evo Morales e seu partido passaram a ser questionados enquanto alternativas suficientes para os povos e nações indígenas do país. Realizo uma análise da situação boliviana, diante desse caso, que reconhece a importância da institucionalização da noção de Vivir Bien nos discursos sobre desenvolvimento do governo de Evo Morales, mas que também percebe o arrolho das políticas públicas relacionadas à terra, ao território e ao direito indígena de existir de acordo com seus próprios modos de produzir e projetar a vida durante esse governo.

Palavras-chave: Bolívia; política indígena; plurinacionalização do Estado; terras baixas. 


\title{
Development and Vivir Bien at the Bolivian Plurinational State
}

\begin{abstract}
The proposal to build a road through the Indigenous Territory and National Park Isiboro Sécure (TIPNIS) triggered a new wave of indigenous mobilizations in Bolivia since 2011. The government, its policies and their proceso de cambio have been questioned as a sufficient alternative to the indigenous people and nations in Bolivia. My study about the Bolivian situation, related to the TINIS case, recognizes the importance of Evo Morales's governmental speeches about development institutionalizing the notion of "Vivir Bien", but also realizes the continued decrease of public policies related to land autonomy, conception of territory and the indigenous right to exist according to their own ways of producing and projecting life lands.

Keywords: Bolivia; indigenous politics; State's plurinationalization; Low-
\end{abstract}

\section{Desarrollo y Vivir Bien en la Bolivia Plurinacional}

Resúmen: La propuesta de construcción de una carretera a traves del Território Indígena y Parque Nacional Isiboro Sécure (TIPNIS) disparó nuevas mobilizaciones indígenas en Bolívia a partir del 2011. El gobierno, sus políticas y el próprio proceso de cambio protagonizado por el presidente Evo Morales y su partido pasaron a ser cuestionados enquanto alternativas suficientes para los pueblos y naciones indígenas del país. Realizo um analisis de la situación boliviana a partir del caso del TIPNIS que reconoce la importância de la institucionalización de la nocion de Vivir Bien en los discursos de sobre desarrollo del gobierno de Evo Morales, pero que también percibe el arrolho de las políticas públicas de ese gobierno relacionadas a la tierra, al território y al derecho indígena de existir de acuerdo a sus propios modos de producir y proyectar la vida.

Palabras clave: Bolívia; política indígena; plurinacionalización del Estado; tierras baja. 


\section{Introdução}

Este artigo discute as tensões e aproximações entre a lógica desenvolvimentista clássica e o projeto boliviano de Vivir Bien a partir da pesquisa que venho realizando sobre os conflitos que envolvem o Território Indígena e Parque Nacional Isiboro Sécure (TIPNIS). Desde o anúncio do projeto de construção de uma estrada através do território a região é palco de intensos conflitos políticos com o governo do presidente Evo Morales e de seu partido, o Movimiento al Socialismo (MAS). O TIPNIS se consolidou, nos últimos anos, como símbolo de oposição política indígena ao projeto de país oferecido pelo MAS, e a análise das reações ao referido projeto viário permitiu lançar luz à diversidade de perspectivas sobre desenvolvimento na Bolívia do Vivir Bien.

A atual proposta de construção de uma estrada através do TIPNIS surge em 2003 com o Decreto 26996, promulgado pelo então presidente da Bolívia, Gonzalo Sánchez de Lozada. Ela foi planejada para ligar as cidades de Villa Tunari (no departamento de Cochabamba) e San Ignacio de Moxos (no departamento de Beni) e se construída terá $306 \mathrm{~km}$ de extensão. De acordo com o projeto apresentado pela empreiteira brasileira OAS, contratada pelo governo boliviano em 2011, a estrada seria dividia em três trechos; o segundo, previsto para ter $177 \mathrm{~km}$, deveria atravessar o TIPNIS. Neste trecho, prevê-se $60 \mathrm{~km}$ atravessando o coração do parque, uma área isolada onde ainda não há contato com os colonos (camponeses que em sua maioria trabalham com a plantação e venda de folha de coca) que já habitam outras regiões da terra indígena. É ao redor da construção deste trecho que começaram as grandes polêmicas sobre a construção da estrada ${ }^{1}$.

A relação do segmento do movimento indígena mobilizado contra a construção da estrada Villa Tunari-San Ignacio de Moxos com a plurinacionalização do Estado boliviano é bastante delicada. Apesar de representar uma das principais frentes de oposição indígena ao governo de Morales, esse segmento, em sua maioria, esteve presente durante o processo constituinte de 2009 e alguns de seus dirigentes apoiaram a primeira candidatura do presidente em 2004. Essa aparente ambiguidade se justifica pela singularidade do processo boliviano de transformação, que institucionalizou um novo universo de possibilidades de movimentação política indígena. Esse novo cenário impactou as organizações indígenas de tal maneira que elas se levantam, agora, contra o próprio setor que organizou o referido processo: os segmentos em resistência reivindicam o cumprimento da Constituição Política do Estado (de 2010), questionam a eficácia do processo de

\footnotetext{
1 Depois da VIII Marcha Indígena realizada em 2011 contra a construção da estrada tanto a OAS quanto o BNDES, o Banco Nacional de Desenvolvimento Econômico e Social (que financiava o projeto), se retiraram da obra. Não há um novo desenho oficial para a construção da estrada.
} 
transformação e exigem que o Estado Plurinacional não seja somente um discurso político de Morales e de seu partido.

Considera-se que a fundação do Estado Plurinacional da Bolívia ocorreu no dia vinte e dois de janeiro de 2010, quando Evo Morales assume seu segundo mandato (2010-2014). Mas com a aprovação da nova Constituição Política do Estado em 2009 e com a redação, em 2006, de um Plano Nacional de Desenvolvimento que negava a lógica desenvolvimentista e propunha em substituição o Vivir Bien, já era possível identificar o início de um processo de mudanças com potencial de provocar profundas transformações no país. Falava-se da construção de uma "Bolivia Digna, Soberana, Productiva y Democrática para Vivir Bien” (Bolívia, 2007). Ainda em curso e tomado por contradições, na prática esse processo refundacional engendra grandes projetos orientados pelo desenvolvimentismo clássico - um modelo econômico, político e uma ideologia/utopia (Ribeiro, 2008) baseada na ideia de progresso, na visão linear do tempo e na concepção na natureza como recurso e como mercadoria.

As noções de Vivir Bien (no caso boliviano) ou de Buen Vivir (no caso equatoriano), inspiradas nas criações e formulações indígenas e originárias, representam a tentativa de validar outras formas de organização da vida que sejam alternativas ao desenvolvimentismo clássico. Justamente por serem inspiradas em formulações que são variadas entre si, as noções de Vivir Bien ou de Buen Vivir não se referem a uma alternativa única ao desenvolvimento, uma alternativa única oferecida pelos povos e nações indígena originário camponeses ${ }^{2}$. Daí a dificuldade em falarmos, nesse momento, do Vivir Bien enquanto um conceito - mesmo que seja ainda um conceito em construção, como afirma Gudynas (2011a).

O Vivir Bien engloba um conjunto de ideias, discursos e práticas que tem sido apresentado e pensado como alternativo ao conceito convencional de desenvolvimento. Recuperando os aportes de Acosta e Choquehuanca, Gudynas (2011) realiza suas analises ao redor do termo Buen Vivir, e não Vivir Bien. A noção é manejada de maneira sutilmente diferente na Constituição equatoriana e boliviana, mas é possível recuperar as reflexões ao redor das duas expressões e organizá-las em um só debate sobre as alternativas ao desenvolvimento forjadas na América do Sul. Assim, este trabalho está preocupado com a realidade boliviana e o manejo da ideia de Vivir Bien, mas também se apoia na literatura que discute o Buen Vivir.

Para Gudynas (2011) existem pelo menos três planos a partir dos quais é possível abordar o Vivir Bien: o plano das ideias, dos discursos e o das práticas. No plano das ideias, o Vivir Bien significa o questionamento às bases conceituais da ideia de desenvolvimento, a compreensão da necessidade de desconstruir a dicotomia entre a natureza e a cultura, a defesa da construção de um repertório legal que inclua os direitos da terra, da natureza, da Pachamama. Enquanto discurso, o Vivir Bien interrompe a celebração do crescimento

\footnotetext{
2 Motivo de dissenso entre o movimento indígena e os constituintes de 2009, o termo indígena originário campesino, como uma unidade, no singular, aparece na nova Constituição Política do Estado (2010) para delimitar esses sujeitos de direito. Para mais informações sobre essa discussão conferir, por exemplo, Albó e Romero (2009) e Schavelzon (2010).
} 
econômico e dos recursos materiais como sinônimos de bem-estar social: "sus apelaciones a la calidad de vida discurren por otros caminos, y además incluyen tanto a las personas como a la Naturaleza" (idem: 2). Já enquanto prática, o Vivir Bien representa uma transformação das ações concretas; nesse campo estão os maiores desafios da noção, "en el sentido de convertirse en estrategias y acciones concretas, que no repitan las posturas convencionales que se critican, y que además sean viables" (idem: ibidem).

Não considero que a identificação desses três aspectos do Vivir Bien dê conta de esgotar o debate sobre a plasticidade dessa noção tal como ela tem aparecido na Bolívia. O Vivir Bien surge como uma variedade de ideias, de discursos e de práticas. Como pude verificar durante os últimos anos de pesquisa na Bolívia, não existem três possibilidades para o Vivir Bien, mas uma multiplicidade delas. Todas essas possibilidades podem, por sua vez, ser organizadas a partir dos três planos apresentados por Gudynas, mas a consequência é o aparecimento de três conjuntos heterogêneos de formulações. Ainda assim, tenho como um dos objetivos deste artigo explorar os sentidos dessa variedade, verificando de perto a heterogeneidade das ideias, dos discursos e das práticas sobre o Vivir Bien a partir do momento em que segmentos indígenas bolivianos passaram a disputar o sentido do desenvolvimento no país, denunciando, muitas vezes, a insuficiência da noção em debate enquanto ideia que de fato poderia reorganizar discursos e práticas na Bolívia.

\section{Vivir Bien: revisões conceituais e rupturas ideais}

O objetivo, nesse primeiro momento, é discutir o Vivir Bien enquanto uma ideia oferecida em substituição ou em concorrência à ideia de desenvolvimento. Na bibliografia investigada o Vivir Bien é apresentado como uma ideia forjada a partir da tentativa de reverter a separação entre a natureza e a cultura e como um modo de produzir e projetar a vida que é essencialmente comunitário. Por isso o Vivir Bien aparece como uma ideologia e utopia que iria de encontro a tudo o que envolve o pensamento desenvolvimentista clássico. As tarefas designadas à noção não são modestas.

Para Gudynas, por exemplo, "el Buen Vivir no es solamente uno más entre otros 'desarrollos alternativos', sino que pone en discusión toda la base conceptual del desarrollo occidental" (Gudynas, 2010, s/p). O debate sobre "desenvolvimentos alternativos" ou "alternativas ao desenvolvimento" é pertinente para essa discussão uma vez que reflete não somente sobre as maneiras de atender às necessidades impostas pela lógica do desenvolvimento, como também sobre a própria consolidação dessa lógica em escala global. No caso boliviano a temática se torna especialmente interessante, pois evidencia as tensões ao redor da tentativa de consolidar um paradigma civilizatório com referências nas cosmologias indígenas que circulam pelo país; paradigma que em seguida é oferecido como uma espécie de desenvolvimento alternativo em 
diálogo com projetos, políticas e instituições sintonizadas com a lógica do desenvolvimentismo clássico. De todas as maneiras, em movimento, o Vivir Bien pode ser percebido como ideia alternativa ao desenvolvimento, como discurso de desenvolvimento alternativo e/ou como prática que permite a reprodução do desenvolvimentismo clássico no país.

O modelo desenvolvimentista começa a se oferecer como pretensamente universal ao final da Segunda Guerra e, nas décadas seguintes, converte-se na grande promessa das duas metades do mundo bipolarizado. A vitória do capitalismo sobre o comunismo ao final da Guerra Fria e o decorrente avanço da universalização dos ideais capitalistas não diminuíram a intensidade do esforço contínuo pela legitimação universal do desenvolvimentismo. Ao contrário, o anseio pelo desenvolvimento dos mercados e das forças produtivas continuou marcando os sistemas econômicos e políticos da maioria dos países do mundo. Mesmo tratando-se de uma ideologia/utopia baseada na necessidade de explorar recursos e povos em nome da atenção das necessidades do mercado e das elites econômicas, o discurso do desenvolvimento quer ser uma possibilidade real para toda a humanidade. Ainda quando marcadamente inalcançável, o desenvolvimento serve como referência de organização da vida em quase todo o globo: trata-se do fortalecimento de um modelo econômico e de uma utopia que "transforma un mundo de visiones en uno homogéneo y universal, donde la vida de las personas viene articulada por los tiempos del mercado y las relaciones medidas por el concepto de 'ciudadanía global”' (De Marzo, 2010: 153).

Para Eduardo Gudynas a homogeneização desse modelo não passou despercebida: "Se cuestionan, por ejemplo, la racionalidad del desarrollo actual, su énfasis en los aspectos económicos y el mercado, su obsesión con el consumo, o el mito de un progreso continuado" (2011: 2). O modelo desenvolvimentista clássico encerra um conjunto de possibilidades que, "en ausencia de un pensamiento fuerte alternativo, se presenta como única $e$ inevitable manera posible para vivir y relacionarse" (De Marzo, 2010: 24). Ainda de acordo com De Marzo, "según el paradigma de civilización occidental, la Tierra no es más que el planeta en el que vivimos. Una definición que legitima la transformación de una infinidad de sujeto 'vivos' en objetos a disposición del desarrollo y del progreso humano" (idem: 164). É nesse contexto que (re)aparecem outros "paradigmas de civilización” que, para De Marzo, seriam baseados "en el modelo milenario de vida de las comunidades originarias".

De acordo com a compreensão dos povos originários dos Andes sulamericanos o Vivir Bien supõe "una idea de la vida y del desarrollo basada en la conciencia de utilizar de la naturaleza sólo lo necesario, para evitar dañar y perjudicar su reproducción, comprometiendo así también los derechos de las generaciones futuras" (De Marzo: 157). O Vivir Bien seria a noção capaz de dar conta de organizar "el conjunto de los esfuerzos orientados a crear las condiciones materiales y espirituales para realizar una vida armónica y feliz" (idem: 161). Idealmente, a promoção do Vivir Bien trata da construção de 
una visión de conjunto entre individuo, comunidad, cultura, naturaleza, seres vivos, derechos y responsabilidad que acaba en un modelo de desarrollo capaz de sostener y hacer crecer a una economía social y solidaria, respetuosa de los ciclos de la vida y, al mismo tiempo, capaz de hacer emerger, dotando de valor, a la independencia entre todos los seres vivos (ídem: 164).

Para Gudynas, o Buen Vivir, ou o Vivir Bien, trataría da criação de "espacios" nos quais "se abandona la pretensión moderna de dominar y manipular todo lo que nos rodea, sean personas o la Naturaleza, para convertirlo en medios que sirven a nuestros fines" (2011: 15). Ainda de acordo com o autor, "en realidad el Buen Vivir se delimita como una plataforma donde se comparten diversos elementos con una mirada puesta en el futuro; posee un horizonte utópico de cambio" (idem: 18). A partir desse horizonte de transformações, se projeta a construção (ou a reconstrução) de outras formas de relação com a natureza - formas de relação que a incluam como parte essencial da vida humana. Para Acosta, "los recursos naturales no pueden ser vistos como una condición para el crecimiento económico, como tampoco pueden ser un simple objeto de las políticas de desarrollo" (2011: 195). Para ele, como para outros autores, a humanidade não está fora da natureza e por isso as políticas econômicas ou as estratégias produtivas não podem ser traçadas como se assim o fosse.

A própria utilização do termo "recursos naturais" é problemática, como também aponta Acosta: a expressão tem como pressuposto a externalidade da natureza em relação à vida humana. Diante da tomada da natureza como recurso, a não destruição é equiparada com o não aproveitamento. A dicotomia entre natureza e cultura sustenta o projeto desenvolvimentista e é sustentada por ele, pois garante que a natureza possa ser tomada como algo externo, disponível e passível de aproveitamento em favor das economias (sejam elas locais, nacionais ou internacionais). O desenvolvimentismo clássico, para operar, precisa que a dicotomia entre a natureza e a cultura ainda funcione. É nesse sentido que o Vivir Bien, enquanto ideia, tem o potencial de desarmar a armadilha desenvolvimentista, propondo a legitimação e inclusive o reconhecimento legal de outras formas de conceber e de se relacionar com a natureza.

Talvez, por tudo isso, o mais importante da discussão seja o reconhecimento do Vivir Bien como um conjunto dinâmico de referências que poderiam desafiar a hegemonia do desenvolvimentismo clássico. Nesse sentido, o oferecimento do Vivir Bien como um modelo de desenvolvimento substituto ao desenvolvimentismo clássico carregaria um paradoxo interno, pois apenas representaria a tentativa de afirmar um novo regime de organização de políticas em substituição de outro, ignorando o que há de mais importante no debate: a necessidade de reconhecer a diversidade e a consequente insuficiência de um paradigma único de felicidade e boa vida.

Sendo assim, é fundamental reconhecer a importância do Vivir Bien enquanto uma ideia desafiadora do estabelecido, mas também é fundamental investigar se sua conversão em política institucionalizada dá conta de manter 
essas características subversoras. Na Bolívia (e no Equador) o termo deixou de ser somente uma ideia e foi apresentado também como um discurso estatal e governamental. É preciso acompanhar o significado desse deslocamento para que seja possível, ao final, perceber o cenário completo no qual os projetos de desenvolvimento de infraestrutura têm sido formulados e realizados.

\section{Surge um novo discurso sobre desenvolvimento na Bolívia}

A principal marca dos discursos estatais que emergiram no contexto da plurinacionalização do Estado boliviano é a desconstrução da equiparação entre crescimento econômico e desenvolvimento do país. O desenvolvimento ainda é mantido como um horizonte desejado, mas para alcançá-lo seria preciso que toda a população da Bolívia vivesse bem. É preciso que o Estado ofereça condições para que o povo viva bem, para que possa e saiba como se alimentar, beber, dançar, dormir, trabalhar, meditar, etc. Trata-se da construção de outro conjunto de referências sobre felicidade e boa vida, e os planos de desenvolvimento do país passam a ser construídos em torno desses discursos.

A institucionalização do Vivir Bien e a sua transformação em discursos políticos e econômicos notoriamente produziu transformações na noção. Se enquanto ideia o Vivir Bien desafia as bases da lógica desenvolvimentista (oferecendo outras possibilidades de relação entre os povos e seus ambientes como alternativas viáveis) enquanto discurso estatal, na Bolívia, o Vivir Bien manifesta-se como uma espécie de desenvolvimento alternativo, o desenvolvimento para Vivir Bien, uma nova variedade produzida a partir das possibilidades que a plasticidade do conceito de desenvolvimento garante.

É possível acompanhar o desdobramento do discurso sobre o desenvolvimento para Vivir Bien no Estado boliviano através da análise de documentos distintos, como a Constituição Política do Estado, aprovada em 2009, os Planos Nacionais de Desenvolvimentos dos últimos governos ou mesmo cartilhas e outros documentos públicos redigidos pelos Ministérios e outras agências do governo. O objetivo dessa seção não é tentar compreender o significado da inclusão dessa noção na Carta Magna do país (principal registro do processo de plurinacionalização da Bolívia) e sim perceber como ela atravessa as instituições bolivianas até se apresentar como um novo discurso sobre desenvolvimento que se materializa na vida das comunidades do TIPNIS. Por isso mesmo não há, neste trabalho, a preocupação em tratar com mais detalhe a questão da Constituição e do Vivir Bien. Por hora vale dizer que Vivir Bien é a base da nova Constituição Política do Estado, é um dos princípios que a organiza - bem como as ideias de unidade, igualdade, inclusão, dignidade, liberdade, solidariedade, reciprocidade, respeito, equidade social e de gênero, responsabilidade e justiça social (Gudynas, 2011: 4). O Vivir Bien, norteando a Constituição, materializa-se como símbolo da plurinacionalização do país, é a insígnia indígena que percorreu o mundo como sinal da vontade de mudança embutida no processo boliviano de transformação. Para Fernández, essa é a 
grande novidade da Constituição do país: "habría que decir que la 'impronta indígena' es su característica principal. Ellos están ahí. Están ahí por muchas cosas" (Fernández, 2009: 46).

$\mathrm{Na}$ Constituição também já estava proposto que o "modelo económico boliviano es plural y está orientado a mejorar la calidad de vida y el vivir bien" (Art. 306). Meu interesse se localiza nesse campo. Por isso, em seguida apresento como o Vivir Bien é manipulado no Plano Nacional de Desenvolvimento da Bolívia de 2006 e quais os tipos de políticas e projetos são organizados sobre a sua vigência enquanto noção norteadora do processo de transformação boliviano. O Plano Nacional de Desenvolvimento aprovado no primeiro mandato do presidente Evo Morales deve ser considerado como o primeiro sinal do processo de transformação que começaria a atravessar as instituições bolivianas e que teve como ápice a Constituinte e a promulgação da nova Constituição Política do Estado, em 2009. Por isso a análise do Vivir Bien como discurso se concentra na apresentação desse documento, buscando entender como a noção basilar do processo de plurinacionalização da Bolívia era apresentada no início do proceso de cambio do país.

O Plano Nacional de Desenvolvimento é dividido em seis capítulos: o primeiro, "Concepción de Desarrollo", apresenta ao público o que é considerado como o desenvolvimento almejado pelo Estado para a população e para o país; o segundo, "Bolivia Digna", trata da necessidade de erradicação da pobreza e das desigualdades na Bolívia; o terceiro capítulo, "Bolivia Democratica", considera o povo boliviano em sua totalidade e em sua variedade como sujeitos responsáveis e capazes de promover o desenvolvimento do país; o quarto capítulo "Bolivia Productiva", propõe a transformação e a diversificação da matriz produtiva boliviana; o quinto, "Bolivia Soberana", anuncia a importância da presença internacional dos povos e nações indígenas, originários e camponeses bolivianos, destacando a necessidade de uma atuação internacional do país que seja soberana e com identidade própria; o último e sexto capítulo "Sostentabilidad Macroeconómica", anuncia a proposta de realização de transformações estruturais na orientação do desenvolvimento do país que deve apontar para a democratização integral, intercultural e diversificada da economia para "generar las condiciones que permitan el Vivir Bien" (Bolívia, 2007: 175). A estabilidade macroeconômica é um requisito para o bom sucesso da proposta de Vivir Bien. Além dos capítulos, o PND conta com uma Introdução e com uma sétima seção, ao final do documento, intitulada "Programa de Inversión Pública 2006-2007”.

Aquela proposta de desenvolvimento nacional estaria baseada na garantia do Vivir Bien tal como ele fosse concebido por cada povo ou nação indígena na Bolívia. O desenvolvimento baseado na promoção do Vivir Bien propõe a substituição dos conteúdos clássicos do desenvolvimentismo (como a dicotomia entre natureza e cultura, a concepção linear do tempo e a fé no progresso, por exemplo) por conteúdos provenientes do encontro entre os povos e as comunidades do país, que respeitem a diversidade e a identidade cultural. "El Vivir Bien", define o documento ao justificar o abandono do conceito 
clássico de desenvolvimento, "es la expresión cultural que condensa la forma de entender la satisfacción compartida de las necesidades humanas, más allá del ámbito de lo material y económico" (idem: ibidem).

O Plano pretende desconstruir a fé evolucionista na ideia de progresso linear, que culmina na divisão errônea das sociedades como modernas/primitivas ou avançadas/atrasadas desenvolvidas/subdesenvolvidas. Para tanto propõe a implementação de um plano de ação baseado na horizontalidade entre os povos, nações e comunidades do país; propõe a promoção do desenvolvimento nacional a partir da recuperação dos vínculos ancestrais das culturas do país com a natureza e com as suas memórias sociais. Dessa maneira o direito da população ao Vivir Bien poderia ser assegurado e é em torno desse projeto que um novo discurso sobre desenvolvimento passa a ser articulado na Bolívia.

Mas os diagnósticos de analistas do país não são otimistas em relação ao potencial de transformação que poderia emergir desses novos discursos. Para Medina (2011), depois de seis anos de gestão de Morales e de manejo do Vivir Bien "el MAS no puede presentar un solo proyecto iniciado de implementación del Vivir Bien" (2011, s/p). A insuficiência viria da incoerência interna do projeto: o Vivir Bien é a estratégia do Plano Nacional de Desenvolvimento, e "en el título del PND ya se da la incoherencia" (idem, s/p). O autor justifica sua descrença: "cuando estos dos paradigmas antagónicos [Desarrollo y Suma Qamaña] se quieren implementar en un espacio político y administrativo, regido por la ratio occidental, como es la 'forma Estado Nación', las buenas intenciones tienen patas cortas" (ídem, s/p). A unilateralidade do desenvolvimento seria relativizada enquanto a profundidade do projeto andino do Suma Qamaña se perderia ao ser traduzido automática e inconscientemente "a parámetros cósicos y cuantificables. De ahí el patético esfuerzo de los funcionarios bolivianos por encontrar 'Indicadores' para medir su implementación en el PND" (Medina, 2011, s/p).

Desde essa perspectiva, as contradições que se reproduzem através das instituições públicas bolivianas preocupadas com os temas de desenvolvimento e da garantia do Vivir Bien seriam engendradas pela própria contradição que emerge da tentativa de conciliar a ideologia/utopia desenvolvimentista com os ensinamentos andinos compilados na ideia de Suma Qamaña. Não seria só a contradição da experiência boliviana, seria a contradição de uma época - na qual as tentativas de abandono da lógica hegemônica ainda são parciais, não dando conta de desmontar os pressupostos lógicos que sustentam o modelo que se almeja superar.

\section{Políticas de desenvolvimento na Bolívia do Vivir Bien}

Ideias, discursos, práticas. A plasticidade do Vivir Bien exige que sua potência seja avaliada em cada uma dessas suas três formas de aparecer. Ao que parece, o Vivir Bien perde energia quando se transporta entre os planos 
apresentados por Gudynas (2011); pretendo comprovar essa proposição argumentando que na prática projetos desenvolvimentistas ainda são planejados sob a vigência institucional e constitucional da noção de Vivir Bien que, portanto, ao apresentar-se na realidade boliviana não é capaz de produzir nenhum tipo de mudança substancial na vida da população do país - menos ainda na vida dos povos indígenas que têm seus territórios ameaçados pelos megaprojetos de desenvolvimento do governo.

Considero o plano da prática como o plano da operacionalização dos discursos institucionais, de formulação das políticas públicas. Mesmo que estejamos diante de um país que fez o Vivir Bien ecoar pelo mundo enquanto um discurso diferenciado sobre desenvolvimento, existem enormes dificuldades de observar políticas públicas, principalmente aquelas relacionadas aos territórios indígenas, que não sejam baseadas na ideologia desenvolvimentista. O caso do TIPNIS é um dos exemplos mais precisos da perpetuação de uma política desenvolvimentista clássica na Bolívia. O Vivir Bien, desde essa perspectiva de análise, é slogan de um governo que quis transformar uma parcela de suas instituições, sem repensar o modelo econômico do país, que segue recuperando e reproduzindo a herança desenvolvimentista dos governos anteriores.

Por ser uma "fuerza social real" (Escobar, 2005: 19) ainda na Bolívia do Vivir Bien, o desenvolvimento continua sendo a ideologia/utopia por trás de projetos de diferentes ordens no país. Mesmo uma análise superficial da caderneta distribuída pelo Ministerio de Planificación del Desarrollo tratando dos logros do PND entre 2006 e 2009 permite observar que o que é considerado como vitória do PND pouco tem a ver com a desconstrução de premissas da lógica desenvolvimentista clássica. Nota-se, por exemplo, a exaltação da realização de obras de infraestrutura viária e produtiva, da reativação da atividade mineira estatal, da exploração de ferro no monte Mutún, da pavimentação média de $276 \mathrm{~km}$ de estrada por ano (em oposição aos $113 \mathrm{~km} /$ ano dos governos anteriores), da criação do Banco de Desenvolvimento Produtivo, do crescimento do Produto Interno Bruto (PIB) do país, do incremento das Reservas Internacionais Líquidas bolivianas, do controle da inflação e do logro do superávit fiscal. Essa série de realizações é importante e representa a consolidação da economia boliviana desde várias perspectivas. Mas também representa a continuidade de uma visão tradicional da economia política do país, ainda percebida desde a lógica do crescimento e do progresso. É difícil ver como o êxito nessas áreas pode significar uma ruptura com o modelo econômico hegemônico rumo à consolidação do Vivir Bien.

No documento distribuído pelo MAS em 2009, o plano de governo de Morales e Linera para as eleições presidenciais daquele ano, também é possível observar que os o presidente e o vice-presidente da Bolívia consideram que para a Bolívia alcançar o Vivir Bien é necessário, por exemplo, uma "Revolução Viária" capaz de integrar o país através da construção de pontes e estradas. Para o período de 2009-2014 era prevista a construção de 4.076km de estradas pavimentadas, número que inclui explicitamente os $306 \mathrm{~km}$ previstos para a 
estrada Villa Tunari-San Ignacio de Moxos (MAS-IPSP, 2009: 93). Diante de tudo isso, a frase que aparece em diferentes outdoors espalhados pela Bolívia deixa de espantar: é possível compreender a assimilação do aparente paradoxo representado na propaganda "Carreteras para Vivir Bien": ele é a expressão da síntese construída pelo governo federal que reproduz o desenvolvimentismo sob a suposta vigência do Vivir Bien.

O problema dessa lógica que busca organizar a implementação do Vivir Bien sem abandonar a noção de desenvolvimento enquanto referência, portanto, é que além de não executar a desconstrução da ideologia/utopia desenvolvimentista no país, ainda ignora uma série de demandas existentes nos territórios por outro tipo de projetos, como pude observar durante os anos em que tenho realizado pesquisas no TIPNIS. Há uma série de propostas, mais e menos sofisticadas, sobre os projetos que são necessários para as comunidades do território. Um universo de proposições sobre como poderia ser a relação entre o Estado e os povos indígenas. Mas concordando outra vez com Medina, é possível dizer que no momento da concepção e execução de projetos "siguieron las inercias desarrollistas”. Ou ainda, como também afirma o autor, é possível dizer que "no se introdujo la economía de reciprocidad en los presupuestos. Ese aprendizaje mínimo no lo tuvo presente el MAS cuando hace del Vivir Bien una política estratégica de valencia constitucional" (Medina, 2011, s/p).

Durante as entrevistas realizadas com comunarios, dirigentes e autoridades do TIPNIS diversas propostas e demandas sobre projetos apareceram. É importante explicitar algumas delas. Diferentemente do que é divulgado pelos segmentos afins ao MAS, os segmentos em resistência ao projeto viário não repudiam a chegada de projetos na região, apenas rechaçam que a construção da estrada seja uma condição para sua realização. A exdirigente indígena Mirian Yubanoré, por exemplo, afirmou que "podrán haber miles proyectos que puedan entrar al TIPNIS, que el gobierno pueda apoyar, que es su deber del gobierno apoyar con proyectos y programas al TIPNIS, pero que lo de de corazón, que lo de sin condiciones, que lo de de buen corazón ¿no?”.

Também para o ex-corregedor Simón Noza a chegada dos projetos na região do Isiboro-Sécure pressuporia, para o governo, a aceitação da estrada através do TIPNIS. Ele afirma que o governo "da proyectos a cambio de que uno acepte la construcción de la carretera”, e é por negarem essas práticas - e não por estarem "en contra del desarrollo" - que os segmentos em resistência às vezes se opõem a alguns dos projetos do governo. Mas eles querem projetos na região e sabem bem que tipo de projetos querem. A partir das entrevistas realizadas sobre essa temática foi possível organizar os projetos demandados no TIPNIS em três conjuntos distintos: projetos de turismo, de infraestrutura e produtivos.

O plano de distribuição dos projetos pelo território tem relação com as necessidades de cada comunidade e com o plano de manejo geral do TIPNIS, que de acordo com o ex-presidente da Sub-Central do TIPNIS, Adrian Nogales, 
foi aprovado em 2001 em uma grande assembleia ${ }^{3}$. Esse plano de manejo foi responsável pela divisão do TIPNIS em diferentes zonas, que podem ser aproveitadas cada uma a sua maneira, de acordo com a resolução das comunidades: "esto no se toca', 'aquí se puede hacer uso tradicional', 'aquí sí se puede hacer uso de recursos"; as comunidades protagonizaram o processo de decisão sobre como produzir no território, de acordo com seus costumes e tradições.

Os projetos devem ser realizados em zonas estratégicas e de acordo com as necessidades reais das comunidades. Nessa perspectiva os projetos são interessantes quando eles dialogam com o que há de singular em cada comunidade, oferecendo soluções para as adversidades da vida cotidiana no TIPNIS. Com o tema dos projetos produtivos a questão fica um pouco mais complicada, porque estamos falando de um espectro mais variado de projetos e de compreensões diversas sobre o que "projetos produtivos" significam e o que eles podem trazer para as comunidades. Para a maioria das pessoas com as quais conversei os projetos produtivos seriam aqueles que poderiam suprir as necessidades produtivas locais e, ao mesmo tempo, oferecer possibilidades de acesso ao dinheiro ou a produtos industrializados.

Os projetos produtivos ideais parecem ser aqueles que conseguem produzir ao mesmo tempo produtos passíveis de comercialização e de utilização nas comunidades. Por isso que durante as entrevistas os projetos pecuários foram sempre destacados como importantes. Eles poderiam garantir acesso à carne a ao leite tanto para as comunidades como para o comércio. Entretanto, alguns dos entrevistados afirmaram que os produtos seriam somente para consumo, enquanto outros afirmaram que seriam para o consumo e para o comércio. Apesar de ser importante apontar essa diferença, a questão não parece fundamental nesse momento. O que é mais interessante nesse debate é a compreensão, essa sim generalizada, de que o território pode ser utilizado em favor das necessidades das comunidades e que o governo pode colaborar com isso garantindo aquilo que é exigido, e não outra coisa.

A resistência, pelo menos nesse momento da vida política e social do TIPNIS, não é à presença do Estado ou das políticas do governo no território: a resistência é à imposição de projetos e políticas que eles não desejam para si. A estrada pode não ser uma necessidade do TIPNIS, mas outros projetos o são. Os projetos que são exigidos pelas comunidades através das organizações indígenas às vezes estão impregnados pela lógica desenvolvimentista clássica ou por alguma variação desse modelo (como projetos relacionados com o extrativismo florestal e baseados na lógica do desenvolvimento sustentável). No fundo, o que está em jogo nesse drama desenvolvimentista (Ribeiro, 2008) é a possibilidade de manutenção, pela população local, da capacidade de ser sujeito do seu próprio destino. Para Nazareth Flores, presidente da Central de Pueblos Indígenas del Beni, o principal é a criação de condições que aprimorem a

3 Os territórios indígenas da Amazônia boliviana são representados por Sub-Centrais, a forma de organização política local. Para mais informações sobre a estrutura do movimento indígena das terras baixas bolivianas conferir Moraes, 2014 . 
relação das pessoas com a sua terra, é o desenvolvimento de projetos produtivos que possam dar mais potência ao modo local de produzir e de projetar a vida.

Existem possibilidades reais de alinhamento das demandas indígenas com os investimentos do governo nesses territórios. Quando observamos que existe um conjunto de reivindicações por projetos de diferentes ordens no território, fica ainda mais difícil de entender porque o governo do Estado plurinacional não reorganiza sua agenda de investimentos na região de maneira a priorizar aquilo que é demandado localmente em detrimento da construção de um projeto viário tão custoso. A resposta deve estar na própria lógica que organiza a agenda de projetos ou, ainda, na lógica que segue sustentando os planos de desenvolvimento do país e os grupos de interesses associados. As reformas institucionais incluíram a proposta do Vivir Bien nos planos de Estado, mas essas reformas convivem com a herança do período anterior, criando novos paradoxos políticos que nem sempre são enfrentados pelo governo: mesmo diante de variadas possibilidades, o Vivir Bien segue pouco mobilizado enquanto influência direta para políticas públicas voltadas aos territórios indígenas na Bolívia.

\section{Conclusão - sobre aquilo que podia ter sido e que não foi}

As pesquisas junto ao TIPNIS revelam a existência de enorme desconfiança em relação ao potencial transformador da institucionalização do Vivir Bien, que compartilho com as pessoas que entrevistei. A estrada é a principal presença do Estado no território, e ela é rechaçada como sinônimo de uma melhoria de vida. Ao contrário do que afirma o governo, para a maioria das pessoas entrevistadas a estrada significa destruição, e não desenvolvimento ou boa vida: "yo creo que esa carretera nosotros no lo vemos como un desarrollo que nosotros vamos a Vivir Bien, eso no lo vemos nosotros. Más bien esa carretera que nos va traer, que quiere el gobierno destruir nuestro territorio, más bien eso nos va destruir" (entrevista com Plácida Muiba). Na mesma entrevista doña Plácida sintetiza os argumentos apresentados até o momento:

\footnotetext{
nosotros no lo vemos ese, que el Vivir Bien que dice el gobierno, cuando vaya a la carretera. Eso no es el Vivir Bien. Porque ya vamos a estar limitados, vamos a estar parcelados y eso yo creo que no es tan así, nosotros no lo vemos tan así. Que eso... sí nosotros ahorita garantizamos que nosotros estamos viviendo el Vivir Bien ahorita así como estamos, tenemos nuestro territorio, estamos en colectividad. En cambio cuando ya estamos en la carretera ya hay artos daños y bueno ya no hay esa tranquilidad y bueno ya no hay ese Vivir Bien ¿no?
}

Por incidirem sobre o Estado e por refletirem sobre um modelo que não começa nem termina em terras bolivianas (o modelo desenvolvimentista), as críticas produzidas nesse território indígena têm potencial de instrumentalizar o debate a respeito das alternativas ao desenvolvimento e dos desenvolvimentos alternativos. Podem, ainda, ser radicalizadas como instrumento das lutas dos povos indígenas, que resistem à imposição do desenvolvimentismo em diferentes partes do planeta. Mesmo que muitas vezes sejam circunstanciais, 
essas críticas carregam a possibilidade de desafiar o estabelecido e, de maneira contundente, questionam a obrigação dos povos indígenas de desenvolverem-se de acordo com o proposto de maneira hegemônica. Não são recusas pontuais a um projeto específico. São, antes, contestações insistentes às tentativas de atropelo dos direitos que aqueles povos têm de existir em seus territórios da maneira como lhes parece mais pertinente. As disputas que marcam o campo do desenvolvimento permanecem nítidas na Bolívia Plurinacional e são protagonizadas ora pelos governos e ora pelas organizações indígenas. O conflito no TIPNIS revelou que noções que ideal e aparentemente são contraditórias, o desenvolvimento e o Vivir Bien, na prática são articuladas, associadas e, às vezes, oferecidas como complementares.

\section{Bibliografia}

ACOSTA, Alberto. "Extractivismo y neoextractivismo: dos caras de la misma maldición" in Más alla del Desarrollo. Quito, Equador: Fundación Rosa Luxemburgo/Abya Yala, 2011, p. 83-118.

ALBÓ, Xavier e Carlos Romero. Autonomías Indígenas en la realidad boliviana y su nueva Constitución. La Paz: Vicepresidencia del Estado Plurinacional de Bolivia; GTZ/PADE, 2009.

BOLÍVIA. Plan Nacional de Desarrollo - Bolivia Digna, Soberana, Productiva y democrática para Vivir Bien 2006 - 2011, 2007. . Constitución Política Del Estado, 2010.

DE MARZO, Giuseppe. Buen vivir - para una democracia de la Tierra. La Paz: Plural Editores, 2010.

ESCOBAR, Arturo. "El 'postdesarrollo' como concepto y practica social". In MATO, Daniel (coord.) Politicas de economia, ambiente y sociedad en tiempos de globalización. Caracas: FaCES, 2005, p. 17-31.

FERNÁNDEZ, Hugo. "Suma qamaña, vivir bien, el ethos de la nueva constitución boliviana”. Revista Obets, 2009, p. 41-48.

GUDYNAS, Eduardo. "Buen Vivir: un necesario relanzamiento". Disponível na internet, 2010.

América Latina en Movimiento, ALAI, n. 462, 2011, p. 1-20.

"Tensiones, contradicciones y oportunidades de la dimensión ambiental del Buen Vivir" in WANDERLEY, Fernanda (Coord.). El Desarrollo en Cuestión: reflexiones desde América Latina. La Paz: CIDES/ UMSA; Plural Editores, 2011a. 
MAS-IPSP. "Bolivia para Vivir Bien. Programa de Gobierno 2010-2015” La Paz: MAS-ISPS, 2009.

MEDINA, Javier. "Suma qamaña, vivir bien y de vita beata. Una cartografía boliviana”. Disponível na internet, 2011.

MORAES, Renata Albuquerque. "Desenvolvimento e Vivir Bien: o caso do Território Indígena e Parque Nacional Isiboro Sécure (Bolívia)”. Dissertação de mestrado. PPG-CEPPAC/UnB, 2014.

RIBEIRO, Gustavo Lins. "Poder, redes e ideologias no campo do desenvolvimento". São Paulo: Novos Estudos, No. 80, 2008, p. 109-125.

SCHAVELZON, Salvador. Assembleia Constituinte da Bolívia: etnografia do nascimento de um Estado Plurinacional. Tese de doutoramento. Museu Nacional/UFRJ, 2010.

Recebido em o9/11/2016. Aprovado em 11/12/2016. 